\title{
RADIOMETRIC CALIBRATION OF ALS DATA FOR ARCHAEOLOGICAL INTERPRETATION
}

\author{
C. Briese, M. Doneus, G. Verhoeven
}

\section{INTRODUCTION}

Airborne laser scanning (ALS, resp. airborne LiDAR) is a widely used data acquisition method for topographic modelling. Due to its ability to accurately and densely sample the terrain surface, it became a commonly used technique for the generation of digital terrain models (DTM). In archaeology, this potential has revolutionised prospection of forested areas (Doneus and Briese, 2006). For the analysis and classification of the topography, geometric criteria derived from the acquired 3D point cloud are typically used. Next to the widely used geometric information, ALS systems typically provide additional information about the recorded signal strength of each echo.

In order to utilize this additional radiometric information for the study of the point-wise backscatter characteristic of the sensed surface, radiometric calibration is essential (Briese et al., 2008; Wagner, 2010). As a result of this radiometric calibration (Briese et al., 2008; Lehner and Briese, 2010) physical quantities (the backscatter cross section $\sigma\left[\mathrm{m}^{2}\right]$, the backscattering coefficient in $\gamma\left[\mathrm{m}^{2} \mathrm{~m}^{-2}\right]$ and the diffuse reflectance measure $\left.\rho_{d}\left[\mathrm{~m}^{2} \mathrm{~m}^{-2}\right]\right)$ that describe the backscatter characteristic of the sensed object at the specific laser wavelength are available.

This publication focuses on the radiometric calibration of ALS data for archaeological interpretation. After the presentation of the radiometric calibration workflow, a full-waveform ALS data set from the case study area Carnuntum (Austria) is investigated. Based on the ALS trajectory and the observables estimated from the decomposition of the full-waveform data set (namely the range, amplitude and echo width per detected ALS echo) the complete ALS data set is calibrated radiometrically. Subsequently the results for the case study area are presented and discussed. This section includes the archaeological interpretation of the resulting radiometric image that can be estimated from the calibrated diffuse reflectance measure $\rho_{d}$ of the ALS point cloud. The final section provides a conclusion and outlook into future work.

\section{RADIOMETRIC CALIBRATION OF ALS DATA}

The physical basis for the proposed radiometric monochromatic calibration of ALS data is the radar equation (Jelalian, 1992). The practical workflow for absolute radiometric correction based on full-waveform ALS data and in-situ reference targets consists of the following steps (c.f. Figure 1 and Briese et al., 2012):

1. Selection of the in-situ reference targets based on the ALS flight plan

2. Determination of the incidence angle dependent reflectance $\rho_{d}$ of the reference surfaces utilising a spectrometer or reflectometer (cf. Briese et al., 2008) that operates at the same ALS wavelength

3. Recording of meteorological data (aerosol type, visibility, water vapour, etc. for the estimation of an atmospheric model) during the flight mission in order to estimate the atmospheric transmission factor

4. Full-waveform decomposition (echo extraction and estimation of echo parameters)

5. Direct georeferencing of the ALS echoes and maybe strip adjustment in order to get an advanced relative and absolute georeferencing of the ALS data

6. Estimation of the local surface normal in order to consider the local incidence angle

7. Estimation of $C_{c a l}$ based on the ALS echoes within the in-situ reference targets (e.g. defined by a polygon area)

8. Radiometric calibration of all echoes based on the determined value of $C_{c a l}$

At the end of this workflow, which can be realised with the program package OPALS (OPALS, 2012), each ALS echo has assigned the additional calibrated diffuse reflectance measure that can be used in the further radiometric analysis of the ALS data.

\section{STUDY AREA}

In order to study the process of radiometric calibration of ALS data for archaeological interpretation of the scene the case study area Carnuntum (Austria) was selected. The ALS data were collected on the $5^{\text {th }}$ of June 2010 (ALS sensor: RIEGL LMS Q-680i). This ALS sensor utilises a laser source for the active illumination and signal detection at a wavelength of $1550 \mathrm{~nm}$. Simultaneous to the aerial data acquisition campaign, in-situ radiometric ground control measurements with a reflectometer (can be seen as a single band spectrometer; the instrument was provided by the company RIEGL) were acquired. The resulting point density (last echo) of the ALS data was higher than 4 points per $\mathrm{m}^{2}$. The radiometric processing of the fullwaveform data set was performed with the software OPALS.

\section{RESULTS AND DISCUSSION}

Figure 2 illustrates the result of the generation of a radiometric image (diffuse reflectance measure $\rho_{d}$ ) of the complete case study area, while Figure 3 provides a detailed view of the calibrated radiometric information over an archaeologically interesting area near Roman Carnuntum's military amphitheatre.

In the lower right part of Figure 3, a first result of an archaeological interpretation of the radiometric information provided by ALS data is presented. It clearly shows that the delineation of different archaeological features is possible with the help of the estimated radiometric information.

\section{CONCLUSION}

This contribution provides first archaeological results for the usage of calibrated radiometric information derived from full- 


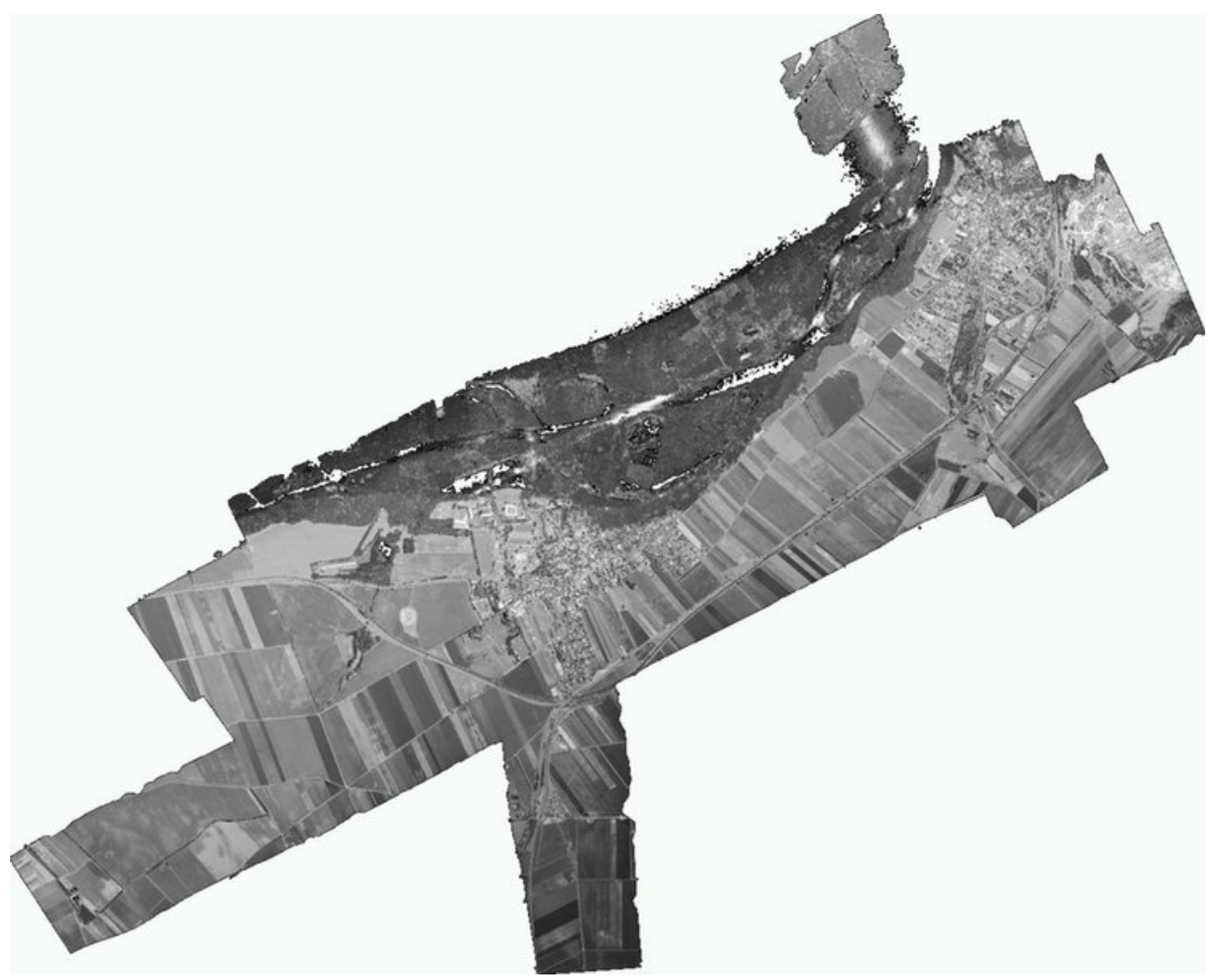

Figure 1: Calibrated radiometric information (diffuse reflectance measure $\rho_{d}$ ) from ALS data for the case study area Carnuntum (approx. $8.2 \mathrm{~km} \times 6.5 \mathrm{~km}$ ).

waveform ALS data. In contrast to passive imagery, the calibrated information from ALS (which utilises a laser source for the active illumination of the sensed surface) is not altered by shadows caused by sun light. Furthermore the resulting images are true-orthophotos due to the fact that the radiometric information is derived for each 3D point and therefore can be located on its correct position.

However, although the first results for ALS radiometry look promising, further research in the application for archaeological interpretation is necessary. Besides a detailed study of the measurement noise and radiometric accuracy, the analysis of further case study areas and the study of multi-temporal behaviour of the ALS radiometry are planned. Additionally, the monochromatic ALS imagery will be compared to simultaneously acquired passive imagery.

\section{ACKNOWLEDGEMENTS}

The Ludwig Boltzmann Institute for Archaeological Prospection and Virtual Archaeology (archpro.lbg.ac.at) is based on an international cooperation of the Ludwig Boltzmann Gesellschaft (A), the University of Vienna (A), the Vienna University of Technology (A), the Austrian Central Institute for Meteorology and Geodynamic (A), the office of the provincial government of Lower Austria (A), Airborne Technologies GmbH (A), RGZMRoman- Germanic Central Museum Mainz (D), RAÄ-Swedish National Heritage Board (S), IBM VISTA-University of Birmingham (GB) and NIKU-Norwegian Institute for Cultural Heritage Research $(\mathrm{N})$.

\section{REFERENCES}

Briese C, Höfle B, Lehner H, Wagner W, PfennigBAUER M, UlLRICH A. 2008. Calibration of full-waveform airborne laser scanning data for object classification. In Proceedings of SPIE Laser Radar Technology and Applications XIII, Turner MD, Kamerman GW (eds.), 6950: 0H1-0H8.

Briese C, Pfennigbauer M, Lehner H, Ullrich A, WAGner W, Pfeifer N. 2012. Radiometric Calibration of Multi-Wavelength Airborne Laser Scanning Data. ISPRS Annals of the Photogrammetry, Remote Sensing and Spatial Information Sciences 37: 335-340.

DONEUS M, BRIESE C. 2006. Digital terrain modelling for archaeological interpretation within forested areas using fullwaveform laserscanning. In The 7th International Symposium on Virtual Reality, Archaeology and Cultural Heritage VAST 2006, Ioannides M, Arnold D, Niccolucci F, Mania K (eds.); 155-162. Jelalian AV. 1992. Laser Radar Systems. Artech House: Boston.

LEHNER H, BRIESE C. 2010. Radiometric calibration of fullwaveform airborne laser scanning data based on natural surfaces. In ISPRS Technical Commission VII Symposium 2010: 100 Years ISPRS - Advancing Remote Sensing Science. International Archives of the Photogrammetry, Remote Sensing and Spatial Information Sciences 38 (Part 7B), Vienna: 360-365. OPALS, 2012. www.ipf.tuwien.ac.at/opals. Homepage of the software OPALS, accessed: October 2012.

WAGNER W. 2010. Radiometric calibration of small footprint full-waveform airborne laser scanner measurements: Basic physical concepts. ISPRS Journal of Photogrammetry and Remote Sensing 65(6): 505-513. 


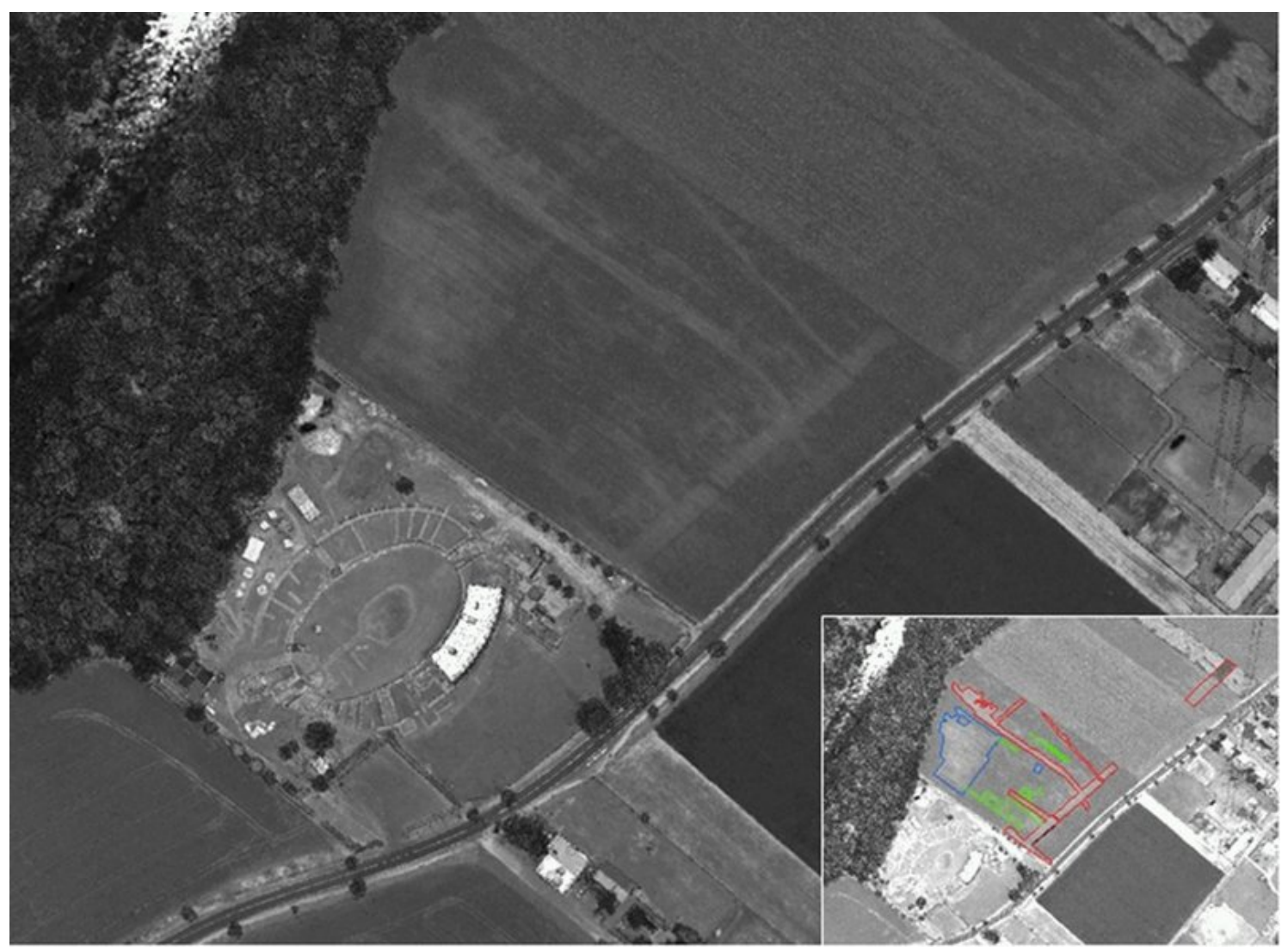

Figure 2: Detailed map of the calibrated radiometric information from ALS data (0.25 m raster size) with archaeological features; the lower right image of the same area displays an archaeological interpretation of the radiometric ALS data.

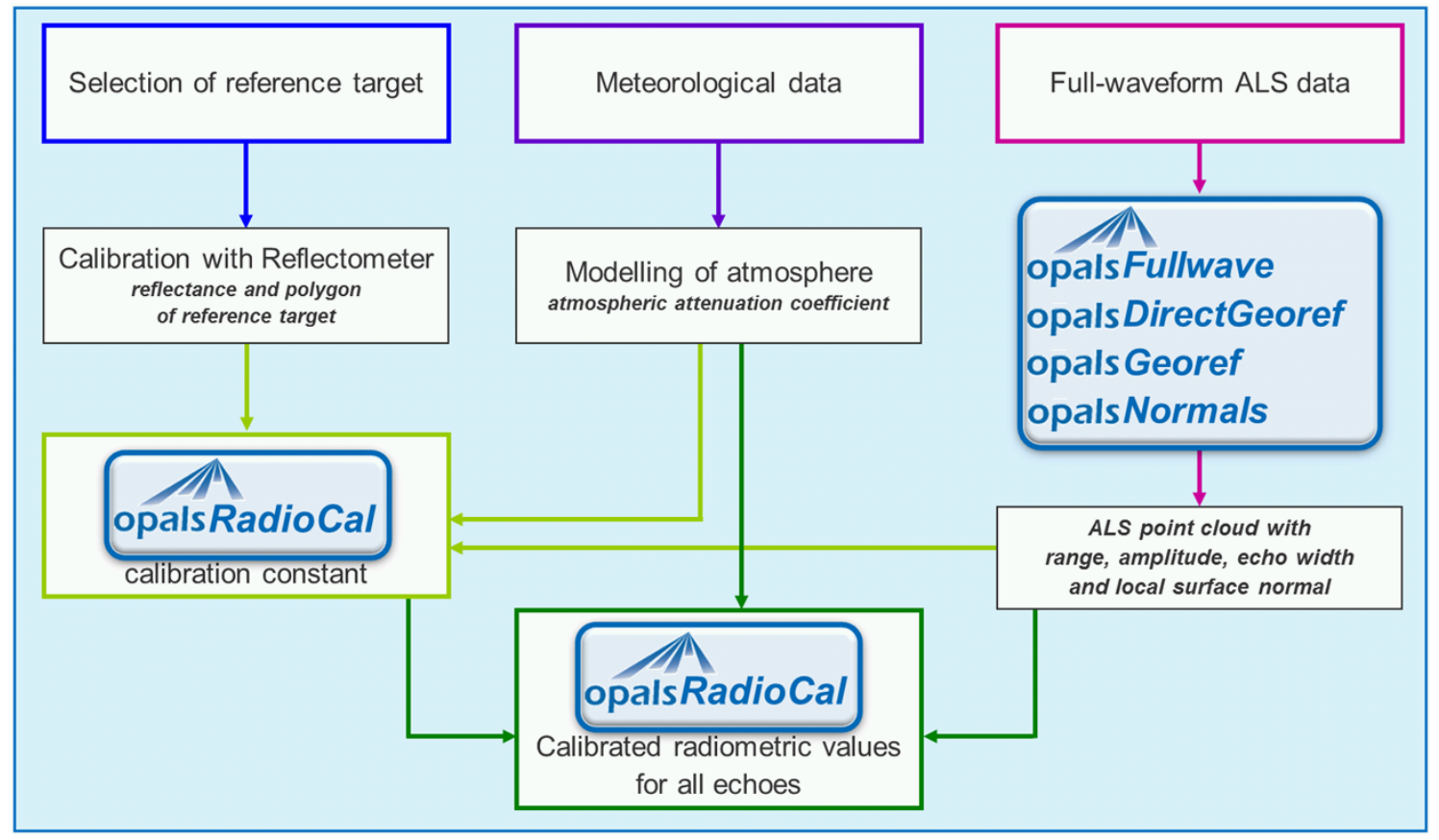

Figure 3: Radiometric calibration workflow (Lehner and Briese, 2010). 